\title{
Sclero-cornea and defective mesodermal migration
}

\author{
ALAN H. FRIEDMAN, SAMSON WEINGEIST, ALVIN BRACKUP AND \\ GERALD MARINOFF \\ From the Department of Ophthalmology, Albert Einstein College of Medicine/ \\ Montefiore Hospital and Medical Center, New York
}

Sclero-cornea is an unusual congenital abnormality which may affect the periphery or the entire cornea (Duke-Elder, 1964). It may occur as an isolated condition (Reese and Ellsworth, 1967; Goldstein and Cogan, 1962) or in association with other ocular or systemic abnormalities (Howard and Abrahams, I 97 I; Bloch, 1965; Desvignes, Poulinquen, Legras, and Guyot, 1967; Kolbert and Seelenfreund, r970; Kanai, Wood, Polack, and Kaufman, 1971). In this case report, we describe pathological findings in a patient who had sclero-cornea and defective mesodermal migration in association with systemic abnormalities.

\section{Case report}

A 5-month-old boy from the Dominican Republic, was admitted to the hospital for treatment of a central corneal perforation in the left eye. The child was the product of a full-term uneventful pregnancy. Delivery was by Caesarean section (as had been the mother's two previous deliveries) and birth weight was $2 \cdot 268 \mathrm{~kg}$. The baby had been in respiratory distress at birth and placed in oxygen for I day. The parents were unrelated and in good health and there had been no history of ocular disease in the family. Five older siblings were normal in all respects. An ocular examination at birth revealed bilateral corneal opacities. At a subsequent evaluation during the neonatal period glaucoma was noted and a goniotomy was performed.

On this admission an eye examination revealed a collapsed left eye with a central corneal perforation through which the retina had prolapsed. The right eye had no perception of light and displayed a gross pendular nystagmus. Intraocular tension by Schiötz tonometer was $35 \mathrm{~mm} \mathrm{Hg}$ in the right eye. Ocular adnexae, lids, and conjunctiva were normal. The cornea (Fig. I) was diffusely cloudy with the periphery like porcelain and resembling sclera. It was flattened anteriorly. Opacification was more dense peripherally and present in all layers of the stroma. No demarcation between sclera

This work was supported in part by National Eye Institute Grant No. EYoo6r 3-05 and by the Seeing Eye, Morristown, New Jersey 07960

Address for reprints: Alan H. Friedman, MD, Montefiore Hospital and Medical Center, 1 I I East 2 loth Street, Bronx, New York 10467, USA

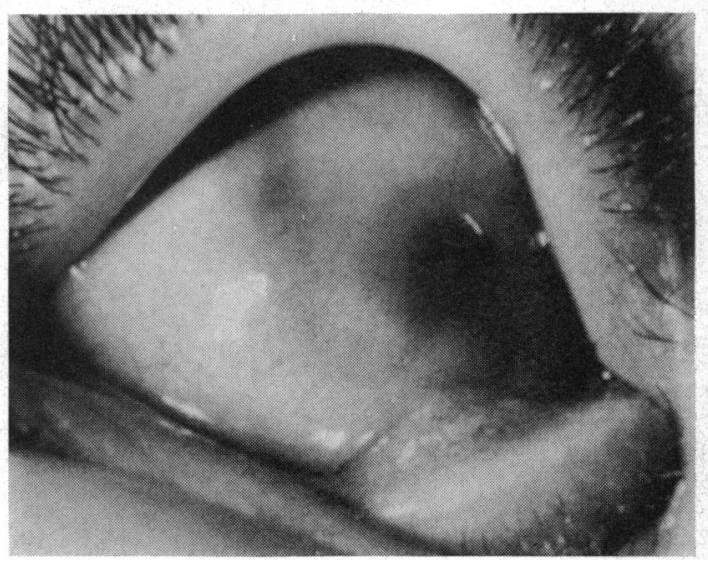

FIG. I External photograph of right eye showing porcelain appearance in the vascularized and anteriorly flattened cornea. The normal corneo-scleral junction is absent

and cornea was apparent. Prominent anastomosing blood vessels extended from the sclera into the cornea. No intraocular structures could be seen.

Physical examination revealed a child with gross motor and growth retardation, probable microcephaly, deafness, low-set ears, ventricular septal defect, hypospadias, and inguinal hernia. All laboratory tests performed were normal and included a normal chromosomal study and negative rubella titre.

\section{PATHOLOGICAL RESULTS}

\section{Gross examination}

A collapsed globe measuring $21.5 \times 17.0 \times 22 \cdot 0 \mathrm{~mm}$ with $4.0 \mathrm{~mm}$ of attached optic nerve. A $3 \mathrm{~mm}$ central corneal perforation was present through which the retina had prolapsed. The remainder of the cornea was opaque and vascularized. On opening the globe, the anterior chamber was obliterated, and the intraocular contents were disorganized.

\section{Microscopic examination}

A central corneal perforation was present through which the retina, vitreous haemorrhage, and fibrinous material had prolapsed (Fig. 2). The corneal epithelium was 


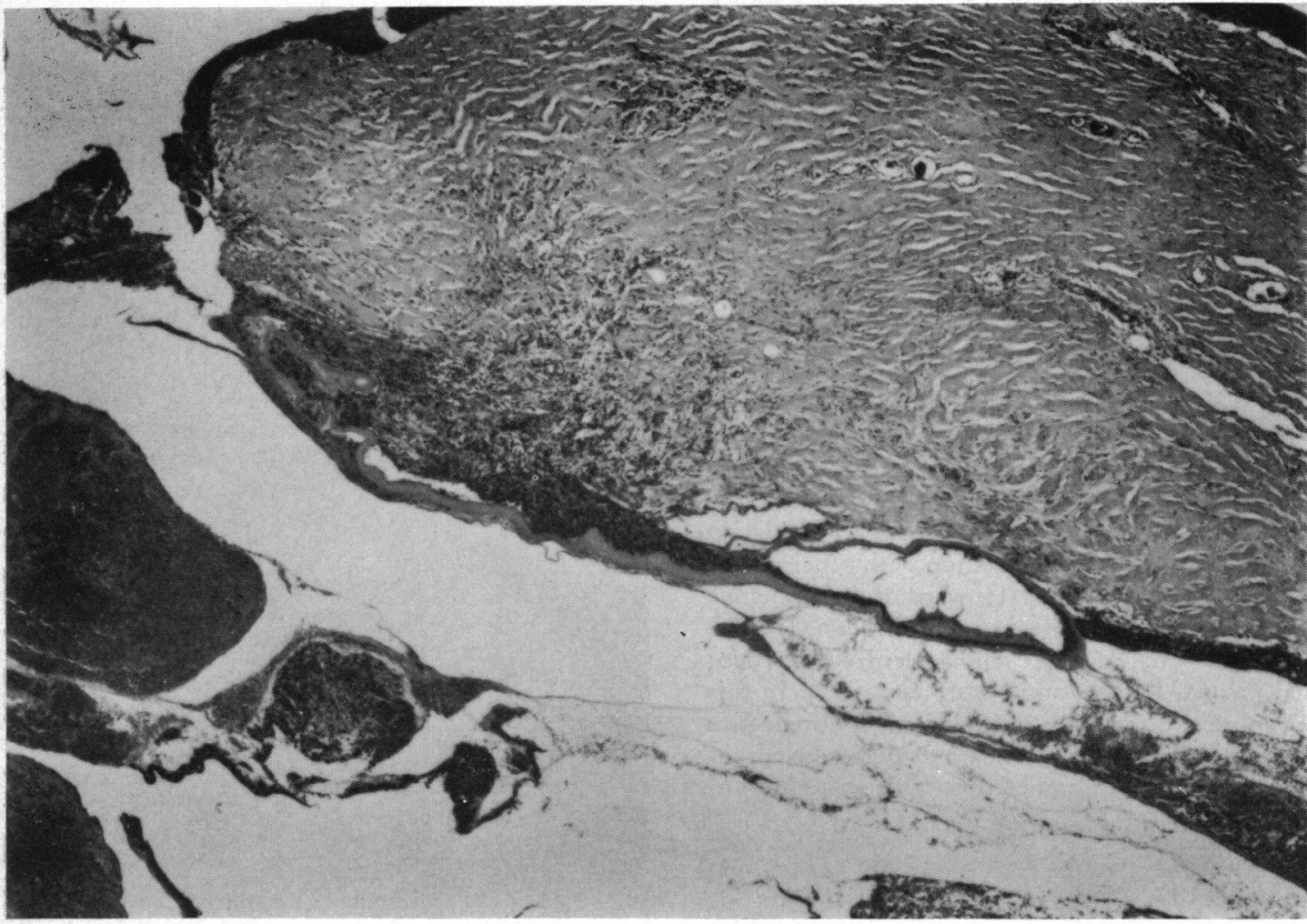

FIG. 2 Photomicrograph of left eye showing central corneal perforation. Fragments of retina seen in opening while lens capsular remnants are adherent to one lip of corneal wound. Thickened corneal lamellae with prominent vessels are present. Note kerato-iridic adhesion at lower right. Haematoxylin and eosin. $\times 112$

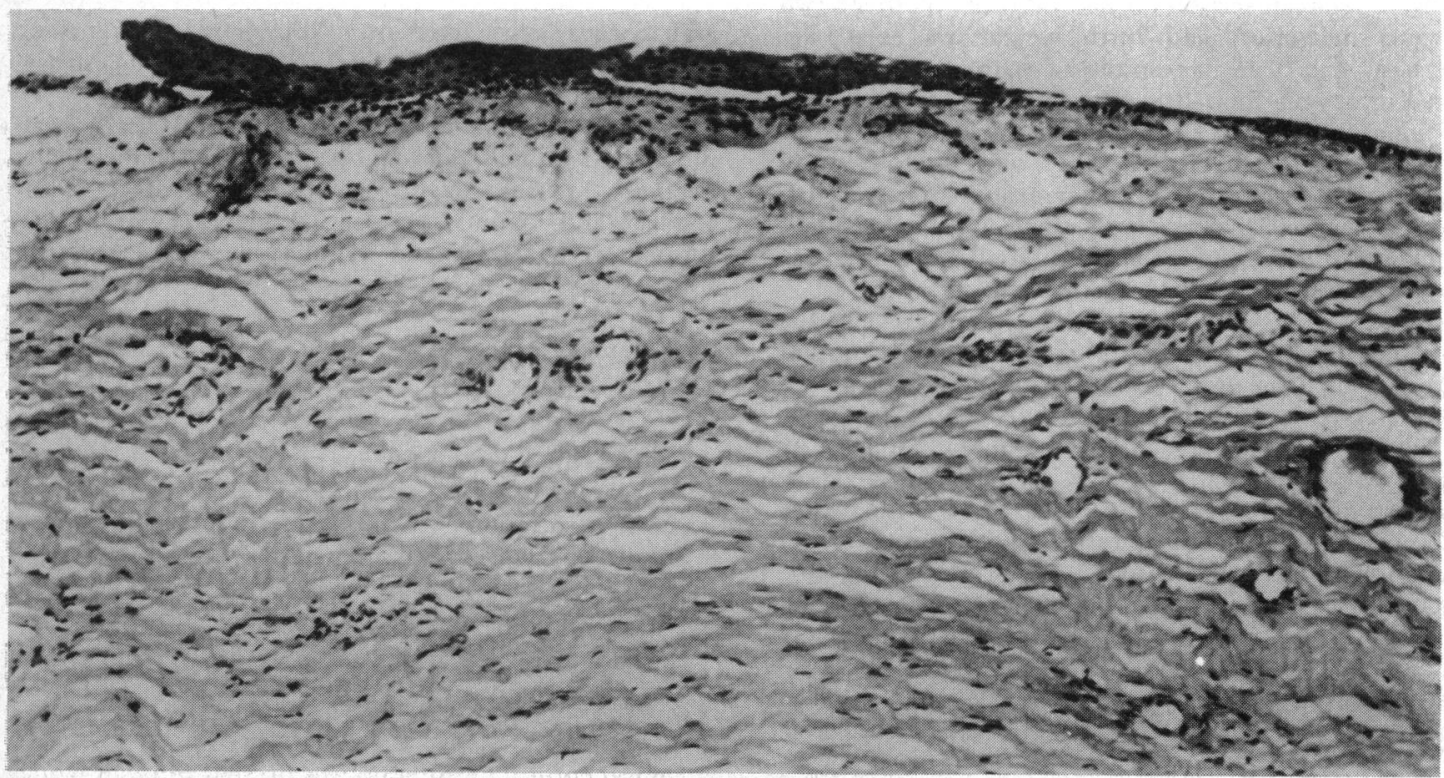

FIG. 3 Photomicrograph of left eye showing portion of abnormal corneal epithelium, absent Bowman's membrane, and stroma composed of irregularly arranged lamellae containing prominent vessels. Haematoxylin and eosin. $\times 3_{1} 5$ 


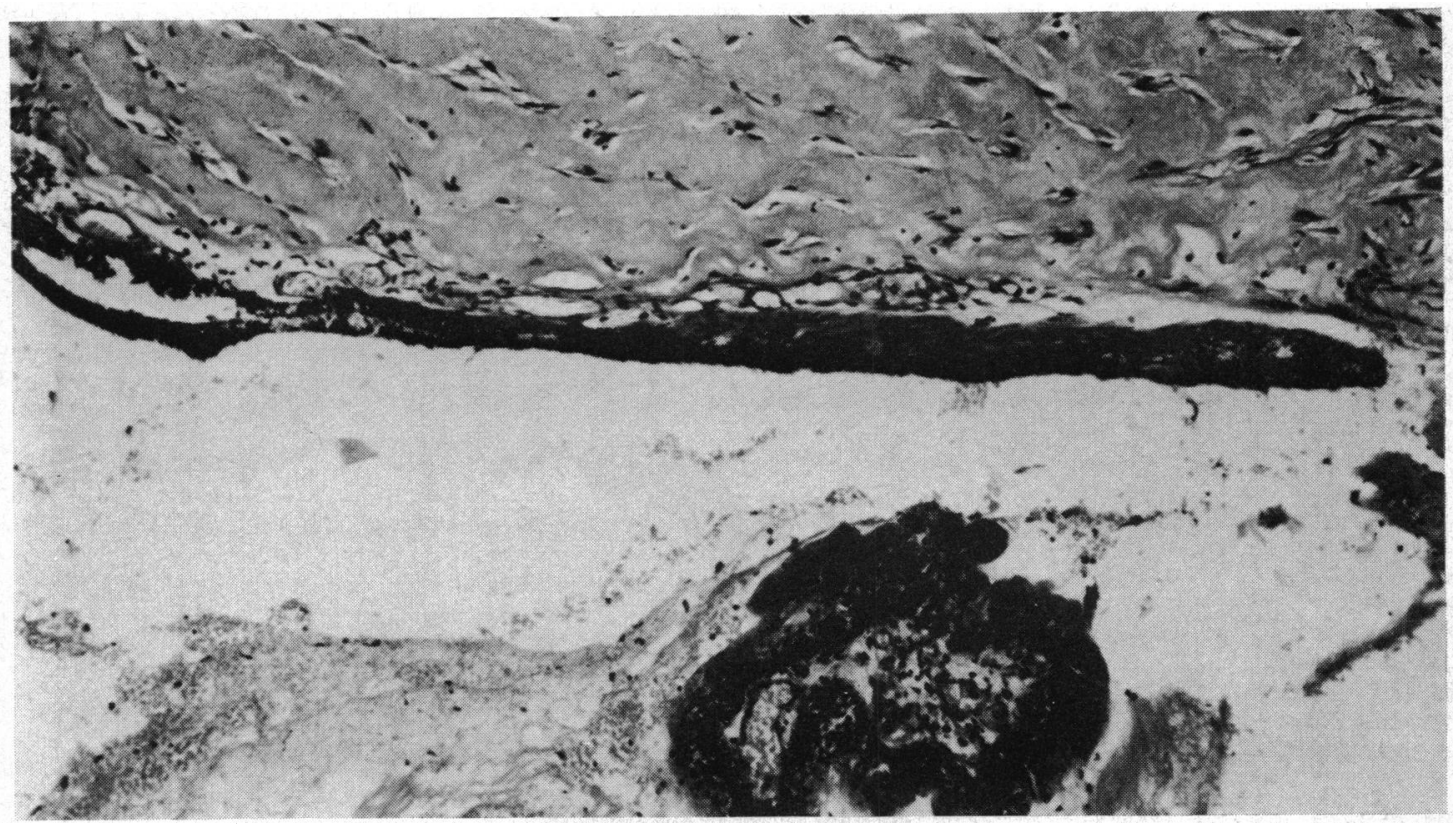

FIG. 4 Photomicrograph of left eye shouing posterior corneal surface. Stromal lamellae markedly thickened. No vessels present. No Descemet's membrane or endothelium present. Total kerato-iridic adhesion. Iris shows pigment epithelial, imuscular, and vascular layers. Note retinal and vitreal elements at bottom. Haematoxylin and eosin. $\times 300$

rregul arly thickened. Bowman's membrane was absent (Fig. 3). The corneal stroma was vascularized at all levels and lamellar fibres were markedly thickened; the thickening in fibre width was more intense at deeper levels where corneal lamellae were thicker than the scleral (Fig. 4). No Descemet's membrane or endothelium was demonstrable (Fig. 4). Centrally at the rupture site the total corneal width was narrower giving the impression of a concave defect of the posterior surface of the cornea. This defect had been filled in by granulation tissue around two large fragments of lens capsule. There were total kerato-iridic adhesions; the anterior chamber was absent, and on one side the pupillary border of the iris was continuous with the equator of the lens (Figs 4 and 5). Here, a remnant of the pupillary membrane was present. The hypoplastic iris consisted of a pigment epithelial layer, a muscle layer, and a vascular layer. Iris stroma was absent. No scleral spur or other angle structures were demonstrable (Fig. 5). Hypoplasia of the ciliary body was present and the ciliary processes, although present, displayed ciliary muscle on one side only. The choroid showed a focal haemorrhagic detachment and choroidal vessels were markedly dilated. The retinal pigment epithelium was unremarkable. A portion of the totally detached retina was present outside the eye. No ganglion cell or nerve fibre layers were seen. Retinal vascularization did not extend to the periphery and more centrally endothelial proliferation was prominent. The peripheral retina was immature and contained one cellular layer in the far periphery and two cellular layers more centrally with no differentiation. Foci of newly formed vessels were present on the retinal surface in the periphery. The optic nerve showed posterior bowing of the lamina and total atrophy. Episcleral vessels were markedly dilated.

\section{Findings}

I. Defective migration of mesodermal tissue

2. Sclero-cornea and cornea plana

3. Glaucoma

4. Persistent pupillary membrane

5. Retinopathy of prematurity

6. Status post-goniotomy

7. Rupture of lens

8. Corneal perforation.

\section{Discussion}

The results of histopathological examination of four corneal buttons and four eyes of patients with sclero-cornea have been described in the literature. The case presented by Goldstein and Cogan (r 962) revealed congenital glaucoma with a normal-sized cornea. Bowman's membrane was absent, the corneal stroma was vascularized, and the posterior surface was irregular and contained central dehiscences in which Descemet's membrane was absent. The iris was adherent to the posterior corneal surface but was otherwise normal. The anterior chamber angle appeared to be normal and the ciliary body was flattened and the processes were attenuated. In Bloch's case (1965) a keratoplasty button showed absence of Bowman's membrane, irregular stromal collagen lamellae, defects in Descemet's 


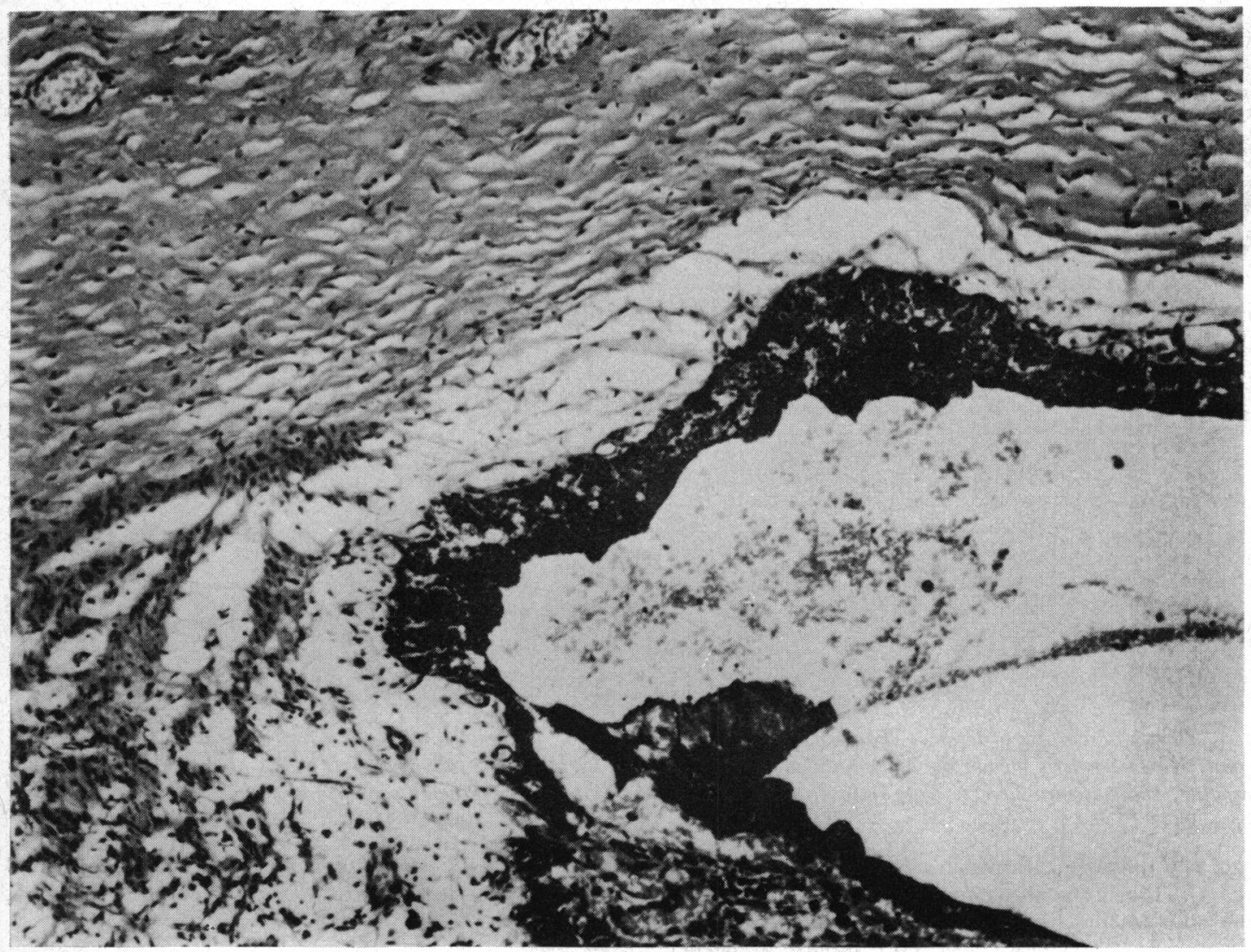

FIG. 5 Photomicrograph of left eye showing area at root of iris. No anterior chamber angle structures are demonstrable. Separation of iris from cornea is artefact. Haematoxylin and eosin. $\times 315$

membrane, and anterior synechiae. Desvignes and others (1967) examined a keratoplasty button and reported the absence of Bowman's membrane, the presence of an irregular Descemet's membrane, endothelium, and a hyaline retrocorneal membrane. Kolbert and Seelenfreund (1970) reported a child with sclero-cornea, anterior cleavage syndrome, and trisomy 18 , in which the eye showed keratinization of the corneal epithelium, Bowman's membrane irregularly thickened or absent, vascularization of the peripheral stroma, and irregular absence of Descemet's membrane and endothelium. Anterior synechiae were present and the anterior chamber was shallow. The trabecular meshwork and Schlemm's canal were present irregularly. Kanai and others (197I) described the fine structure of a keratoplasty button. They reported an absent Bowman's membrane, and increased and variable diameter of corneal collagen fibres, thicker anteriorly and thinner posteriorly. Vascularization was present in the anterior and middle stroma. A thin underdeveloped Descemet's membrane was present and the endothelium was absent. Townsend, Font, and Zimmerman (1974), in their exhaustive study of congenital corneal leucomas, described a case of sclero-cornea which displayed an oedematous detached corneal epithelium, absent Bowman's membrane, and replacement of the outer two-thirds of stroma by thick irregular collagen bundles which were continuous with and indistinguishable from those of sclera. A focal remnant of Descemet's membrane was seen in the periphery. Keratoiridic adhesions were present in the midperiphery and periphery. A normal lens was present and the ciliary body was hypoplastic. Rodriguez, Calhoun, and Weinreb (1974) reported a case of sclerocornea in association with an unbalanced chromosomal translocation ( $\mathrm{r} p \mathrm{p}, \mathrm{r} / \mathrm{q})$. Histopathological examination revealed a corneal epithelium containing scattered cytoplasmic vacuoles, the presence of Bowman's membrane in a few central areas, no differentiation between cornea and sclera, and thickened stromal lamellae with vascularization in the superficial third. Descemet's membrane was 
present paracentrally and towards the periphery as a thin irregular basement membrane lined by endothelial cells. The anterior chamber angle contained a few strands of mesodermal tissue bridging it. The uveal teact was unremarkable. March and Chalkley (1974) reported a girl with sclero-cornea and a Dandy-Walker cyst in whom a penetrating keratoplasty was performed. The histopathological report was limited to a description of the corneal stroma containing bizarrely orientated collagen fibrils and a central absence of Descemet's membrane and endothelium. Our case displayed the typical clinical and histopathological features of sclerocornea. Rupture of the lens and the attendant fibrovascular reaction was presumably secondary to the goniotomy. In addition there was evidence of defective mesodermal migration which resulted in absence of Descemet's membrane and endothelium, lack of angle structures, and iris stromal and ciliary stromal hypoplasia. Of all the cases of sclero-cornea previously reported which had associated mesodermal abnormalities, our case displayed the most severe retardation of development of layers derived from mesoderm. Sclero-cornea can exist, however, in the presence of a wide spectrum of mesodermal abnormalities as shown by the varying histopathological findings in the previously reported cases.

The mesodermal manifestations of sclerocornea may represent a defect in mesodermal formation resulting from an arrest at varying stages of embryonic development. Normal development of the anterior segment of the eye is predicated upon the migration of three successive waves of mesoblastic cells derived from the paraxial mesoderm at the margin of the optic cup (Seefelder, 1920).
Corneal endothelium is formed during the first wave at the $11-12 \mathrm{~mm}$ stage, corneal stroma in the second at $13-14 \mathrm{~mm}$, and iris stroma in the third at $18 \mathrm{~mm}$. The ocular vascular system also develops from the paraxial mesoderm. The annular vessel which develops at the anterior end of the optic cup gives rise to the anterior portion of the tunica vasculosa lentis (beginning at the $17 \mathrm{~mm}$ stage) and the lamina iridopupillaris (22 $\mathrm{mm}$ stage). From this lamina develop the superficial mesodermal layer of the iris and the pupillary membrane.

As orderly development proceeds, the corneoscleral anlage appears at the 20 to $30 \mathrm{~mm}$ stage. The canal of Schlemm is demonstrable at the 65 mm (third month) and the scleral spur by the fifth month. The findings in our case thus represent manifestations of an arrest in mesodermal development occurring at the earliest stages of mesodermal differentiation.

\section{Summary}

A 5-month-old boy with bilateral sclero-cornea, multiple systemic abnormalities, and normal karyotype had his left eye removed after corneal perforation. Histopathological examination of the enucleated eye revealed an irregular corneal epithelium, absent Bowman's membrane, thickened and vascularized stromal lamellae, absent Descemet's membrane and endothelium, no angle structures, hypoplasia of the iris and ciliary body, and total kerato-iridic adhesions. A profound defect in embryogenesis due to defective mesodermal migration during the earliest phase of mesoderm differentiation is postulated as the causative factor in this case.

\section{References}

BLOCH, N. (1965) F. Génét. hum., 14, 133

DeSVignes, P., POULINQUen, Y., LEgras, M., and GUYOT, J. D. (1967) Arch. Ophtal. (Paris), 27, 43

DUKE-ELDER, S. (1964) 'System of Ophthalmology', vol. 3, pt. 2, p. 591. Kimpton, London

goldstein, J. E., and Cogan, D. G. (1962) Arch. Ophthal., 67, 76r

hOWARD, R. O., and ABrahams, I. W. (197r) Amer. F. Ophthal., 71, 254

kANAI, A., WOOD, T. C., POLACK, F., and KaUfman, H. E. (1971) Invest. Ophthal., 10, 687

KOLBERT, G. S., and SEELENFreUnd, M. (1970) Ann. Ophthal., 2, 26

MARCH, W. F., and CHALKLEY, T. H. F. (1974) Amer. F. Ophthal., 78, 54

REESE, A. B., and ELlsWORTH, R. M. (1967) Arch. Ophthal., 75, 307

rodriguez, M. M., Calhoun, J., and weinreb, s. (1974) Amer. F. Ophthal., 78, 49

SEEFELDER, R. (1920) Klin. Mbl. Augenheilk., 65, 539

TOWNSEND, W. M., FONT, R. L., and ZIMMERMAN, L. E. (1974)

Amer. F. Ophthal., 77, 400 